\title{
Effect of dietary sugar concentration and sunflower seed supplementation on lactation performance, ruminal fermentation, milk fatty acid profile, and blood metabolites of dairy cows
}

\author{
A. Razzaghi, ${ }^{*}$ R. Valizadeh, ${ }^{* 1}$ A. A. Naserian, ${ }^{*}$ M. Danesh Mesgaran, ${ }^{*}$ A. J. Carpenter, $\dagger$ and M. H. Ghaffari ${ }^{* 2}$ \\ *Department of Animal Science, Faculty of Agriculture, Ferdowsi University of Mashhad, PO Box 91775-1163, Mashhad, Iran \\ †Department of Animal Sciences and Industry, Kansas State University, Manhattan 66506
}

\begin{abstract}
Previous research has shown that both sunflower seed (SF) and sucrose (SC) supplementation can result in variation in milk fat concentration and composition, possibly due to altered fermentation patterns and biohydrogenation of fatty acids in the rumen. The objective of this study was to determine the effects of different sugar concentrations with or without SF supplementation on lactation performance, ruminal fermentation, and milk fatty acid profile in lactating dairy cows. Eight multiparous Holstein dairy cows (body weight $=620 \pm$ $15 \mathrm{~kg}, 60 \pm 10 \mathrm{~d}$ in milk, mean \pm standard deviation) were randomly assigned to treatments in a replicated 4 $\times 4$ Latin square design with a $2 \times 2$ factorial arrangement of treatments. Each 21-d period consisted of a 14-d diet adaptation period and 7-d collection period. Dairy cows were fed 1 of the following 4 diets: (1) no additional SC without SF supplementation (NSC-SF), (2) no additional SC with SF supplementation (NSC+SF), (3) SC without SF supplementation (SC-SF), and (4) SC with SF supplementation $(\mathrm{SC}+\mathrm{SF})$. The diets contained the same amount of forages (corn silage and alfalfa hay). Four isonitrogenous and isoenergetic diets were formulated by replacing corn grain with SC and $\mathrm{SF}$ and balanced using change in proportions of canola meal and sugar beet pulp. No interaction was detected between SC and SF supplementation with respect to dry matter intake, milk yield, and composition. A tendency was found for an interaction between inclusion of $\mathrm{SC}$ and SF on energy-corrected milk with the highest amount in the SC-SF diet. Ruminal pH and the molar proportion of acetate were affected by SC inclusion,
\end{abstract}

\footnotetext{
Received October 26, 2015.

Accepted December 8, 2015.

${ }^{1}$ Corresponding author: valizadeh@um.ac.ir

${ }^{2}$ Current address: Department of Agricultural, Food, and Nutritional Science, University of Alberta, Edmonton, T6G 2P5, Canada.
}

with an increase related to the SC-SF diet. Diets containing SF decreased the concentrations of short-chain fatty acids (4:0 to 10:0) and medium-chain fatty acids (12:0 to 16:0) in milk fat. The addition of SC tended to decrease the concentration of total trans-18:1. These data provide evidence that exchanging $\mathrm{SC}$ for corn at $4 \%$ of dietary dry matter influenced milk fat content and rumen $\mathrm{pH}$, resulting in a tendency for decreased concentration of trans-18:1 in milk fat. Sucrose alone did not alter the milk fatty acid profile when cows were fed a combination of unsaturated fat and sugar, although several significant interactions between sugar and unsaturated fat were observed.

Key words: sucrose, sunflower seed, fatty acid profile, dairy cow

\section{INTRODUCTION}

It is well known that nutrition is a major factor determining the concentration and secretion of specific fatty acids in dairy cow milk (Chilliard et al., 2007; Shingfield et al., 2008). Although fat supplementation can increase the energy density of a ration, fat itself, particularly unsaturated fats, can have adverse effects on rumen fermentation. Incomplete biohydrogenation (BH) of UFA is a major cause of milk fat depression, which is defined as the decrease in milk fat synthesis mainly due to the formation of several trans-fatty acid isomers during ruminal $\mathrm{BH}$, which exert anti-lipogenic effects (Shingfield et al., 2010). Thus, feeding vegetable oils or oilseeds to dairy cows may reduce the milk fat concentration and yield. Studies in ruminants have shown that inclusion of sunflower oil in the diet increases both cis-9,trans-11 18:2 and trans-11 18:1 content in milk (Roy et al., 2006) at the expense of the short- and medium-chain fatty acids (Glasser et al., 2008; Razzaghi et al., 2015).

Sugars can be used in a high-concentrate diet to replace a portion of corn grain. Indeed, replacing corn by sucrose (SC) or molasses has been shown in some 
instances to increase DMI, milk fat concentration, and alter milk fatty acid profile (Broderick et al., 2008; Penner and Oba, 2009; Martel et al., 2011). Feeding supplemental sugar to dairy cows has been shown in some instances to increase ruminal $\mathrm{pH}$ (Penner and Oba, 2009) and ruminal butyrate concentration (Martel et al., 2011), and decrease ruminal propionate (DeFrain et al., 2004). In the literature, the effect of sugars on milk yield is variable, with some studies reporting increases in milk yield (Broderick and Radloff, 2004) and others reporting no effect of sugar inclusion on milk yield (Broderick et al., 2008). As opposed to unsaturated fat supplementation, accumulating evidence indicates that sugar significantly decreases the proportions of both polyunsaturated (Mullins and Bradford, 2010) and trans-18:1 fatty acid (Penner and Oba, 2009) in milk fat and increases milk fat content (Broderick et al., 2008). Martel et al. (2011) reported that molasses may promote mammary de novo fatty acid synthesis in cows fed high-energy rations by moderating ruminal $\mathrm{pH}$ and altering ruminal fatty acid $\mathrm{BH}$ pathways. Complete $\mathrm{BH}$ of UFA eliminates potential negative effects of specific BH intermediates (trans-fatty acid) on milk fat synthesis (Shingfield et al., 2010); therefore, sugar may be capable of mitigating the potential adverse effects on milk fat synthesis. However, Razzaghi et al. (2015) failed to find enhancement of ruminal pH, milk fat concentration, and significant alterations in milk fatty acid profile when feeding SC (total sugar; $8.7 \%$ of DM) to dairy goats.

Some evidence has been found for interactions between sunflower oil and carbohydrates in the diet. Zened et al. (2013) observed that when sunflower oil, rich in cis-9,cis-12 18:2, was added to the diet, the ruminal $\mathrm{pH}$ did not change and the proportion of trans-11 $\mathrm{BH}$ intermediates in the rumen content greatly increased; however, the association of increasing starch level and adding sunflower oil to the diet of cows resulted in trans-10 fatty acid increasing at the expense of trans-11 fatty acid. In the current study, we hypothesized that PUFA and trans-fatty acid proportions in milk fat are lower when cows are fed SC compared with no supplemental SC diets. Furthermore, it is possible that the dietary sugar content and dietary cis-9,cis-12 18:2 supplementation interact to alter the pathways of rumen $\mathrm{BH}$, resulting in changes in the specific fatty acid contents in milk fat. To confirm this hypothesis, we investigated the effects of feeding diets containing different total sugar contents ( $\sim 4.7$ vs. $8.9 \%$ of dietary DM) with or without ground sunflower seed (SF) supplementation (8 vs. 0\% of dietary DM) to dairy cows on productivity, ruminal fermentation, and milk fatty acid profile.

\section{MATERIALS AND METHODS}

\section{Cows, Experimental Design, and Treatments}

The experiment was conducted at the Research Farm of the Faculty of Agriculture, Ferdowsi University of Mashhad (Iran) according to the guidelines of the Iranian Council of Animal Care (1995). Eight multiparous Holstein dairy cows $(\mathrm{BW}=620 \pm 15 \mathrm{~kg}, 60 \pm 10$ DIM, mean $\pm \mathrm{SD}$ ) were randomly assigned to treatments in a replicated $4 \times 4$ Latin square design with a $2 \times 2$ factorial arrangement. Cows were fed TMR for ad libitum intake. Each 21-d period consisted of a 14-d diet adaptation period and 7-d collection period. Dairy cows were fed 1 of the following 4 diets: (1) no additional SC without SF supplementation (NSC-SF), (2) no additional SC with SF supplementation (NSC+SF), (3) SC without SF supplementation (SC-SF), and (4) SC with SF supplementation (SC+SF). Sucrose at $4 \%$ and ground $\mathrm{SF}$ at $8 \%$ of diet DM were included by replacing corn grain to create dietary treatments (Table 1). All diets were formulated to be isoenergetic and isonitrogenous; therefore, diets with SF supplementation contained less canola meal and more sugar beet pulp level compared with unsupplemented diets, because sugar beet pulp is relatively low in energy and protein contents. Sunflower seed was chosen because of its richness in cis-9,cis-12 18:2 as a main substrate for BH. Diets were formulated using the Cornell-Penn-Miner System (CPM Dairy, version 3.0.8; Cornell University, Ithaca, NY; University of Pennsylvania, Kennett Square, PA; and William H. Miner Agricultural Research Institute, Chazy, NY) to supply adequate $\mathrm{NE}_{\mathrm{L}}$ for a $600-\mathrm{kg}$ cow producing $40 \mathrm{~kg}$ of milk with a fat concentration of $3.5 \%$. Cows were housed in tie stalls and allowed to exercise for $1 \mathrm{~h}$ every afternoon. Cows were fed individually at 0800,1600 , and $2400 \mathrm{~h}$ for 5 to $10 \%$ refusals, and DMI was recorded daily. They were milked 3 times per day at 0700,1500 , and $2300 \mathrm{~h}$, and milk production was recorded at each milking.

\section{Sampling Procedures}

Feed intake and milk yield were measured daily in the last $7 \mathrm{~d}$ of the experiment. Samples of the diets were taken weekly, frozen, and pooled on a 3 -wk basis. Composited samples were mixed thoroughly and subsampled for chemical analyses. Milk samples were obtained from the last $7 \mathrm{~d}$ of each period. One sample was stored at $4^{\circ} \mathrm{C}$ with a preservative (potassium bichromate) for milk component analysis. Another sample without preservative was stored at $-20^{\circ} \mathrm{C}$ for analysis of milk fatty acid profile by gas chromatography. Energy-corrected milk 
Table 1. Ingredients and chemical composition of experimental diets

\begin{tabular}{|c|c|c|c|c|}
\hline \multirow[b]{2}{*}{ Item } & \multicolumn{4}{|c|}{ Dietary treatment ${ }^{1}$} \\
\hline & NSC-SF & $\mathrm{NSC}+\mathrm{SF}$ & SC-SF & $\mathrm{SC}+\mathrm{SF}$ \\
\hline \multicolumn{5}{|l|}{ Ingredient (\% of DM basis) } \\
\hline Alfalfa hay & 18 & 18 & 18 & 18 \\
\hline Corn silage & 21 & 21 & 21 & 21 \\
\hline Barley grain & 15 & 15 & 15 & 15 \\
\hline Corn grain & 14 & 6 & 10 & 2 \\
\hline Ground sunflower seed $^{2}$ & - & 8 & - & 8 \\
\hline Sucrose & - & - & 4 & 4 \\
\hline Soybean meal $(45 \% \mathrm{CP})$ & 10 & 10 & 10 & 10 \\
\hline Cotton seed meal & 6 & 6 & 6 & 6 \\
\hline Canola meal & 3 & - & 4 & 1.5 \\
\hline Meat meal & 4 & 4 & 4 & 4 \\
\hline Sugar beet pulp & 4 & 7 & 3 & 5.5 \\
\hline Wheat bran & 3 & 3 & 3 & 3 \\
\hline Vitamin and mineral premix ${ }^{3}$ & 1 & 1 & 1 & 1 \\
\hline Limestone & 0.5 & 0.5 & 0.5 & 0.5 \\
\hline Salt & 0.5 & 0.5 & 0.5 & 0.5 \\
\hline \multicolumn{5}{|l|}{ Chemical composition (\% of DM) } \\
\hline $\mathrm{NE}_{\mathrm{L}}^{4}(\mathrm{Mcal} / \mathrm{kg}$ of $\mathrm{DM})$ & 1.64 & 1.66 & 1.65 & 1.68 \\
\hline $\mathrm{DM}(\%$ as fed $)$ & 56.9 & 57.2 & 57.2 & 57.4 \\
\hline $\mathrm{OM}$ & 91.4 & 90.6 & 91.1 & 90.8 \\
\hline $\mathrm{CP}$ & 18.3 & 18.2 & 18.2 & 18.2 \\
\hline NDF & 31.9 & 34.1 & 31.5 & 33.6 \\
\hline $\mathrm{ADF}$ & 19.7 & 21.9 & 20.0 & 21.8 \\
\hline Ether extract & 3.5 & 6.4 & 3.5 & 6.2 \\
\hline NFC & 40.8 & 35.9 & 41.5 & 36.6 \\
\hline Starch & 25.2 & 19.4 & 22.3 & 16.6 \\
\hline Total ethanol-soluble carbohydrates ${ }^{5}$ & 4.7 & 4.7 & 8.6 & 8.9 \\
\hline \multicolumn{5}{|c|}{$\begin{array}{l}{ }^{1} \text { Dietary treatments: NSC-SF }=\text { no additional sucrose }(\mathrm{SC}) \text { without sunflower seed }(\mathrm{SF}) \text { supplementation; } \\
\mathrm{NSC}+\mathrm{SF}=\text { no additional } \mathrm{SC} \text { with } \mathrm{SF} \text { supplementation; } \mathrm{SC}-\mathrm{SF}=\mathrm{SC} \text { without } \mathrm{SF} \text { supplementation; and SC+SF } \\
=\mathrm{SC} \text { with SF supplementation. }\end{array}$} \\
\hline \multicolumn{5}{|c|}{$\begin{array}{l}{ }^{2} \text { Sunflower seed contained (\% of total FAME): } 16: 0 \text { (5.59), cis-16:1 (0.09), 18:0 (3.70), cis-18:1 (33.04), } \\
\text { trans-18:2 (0.79), cis-18:2 (53.89), cis-18:3 (0.70), 20:0 (0.35), cis-20:1 (0.31), 22:0 (0.94), and 24:0 (0.32). }\end{array}$} \\
\hline \multicolumn{5}{|c|}{$\begin{array}{l}{ }^{3} \text { Each kilogram of the vitamin-mineral premix contained (DM basis): vitamin A }(50,000 \mathrm{IU}) \text {, vitamin } \mathrm{D}_{3} \\
(10,000 \mathrm{IU}) \text {, vitamin } \mathrm{E}(0.1 \mathrm{~g}) \text {, calcium }(196 \mathrm{~g}) \text {, phosphorus }(96 \mathrm{~g}) \text {, sodium }(71 \mathrm{~g}) \text {, magnesium }(19 \mathrm{~g}) \text {, iron }(3 \\
\mathrm{g}) \text {, copper }(0.3 \mathrm{~g}) \text {, manganese }(2 \mathrm{~g}) \text {, zinc }(3 \mathrm{~g}) \text {, cobalt }(0.1 \mathrm{~g}) \text {, iodine }(0.1 \mathrm{~g}) \text {, and selenium }(0.001 \mathrm{~g}) \text {. } \\
{ }^{4} \text { According to CPM Dairy (Cornell University, Ithaca, NY). }\end{array}$} \\
\hline
\end{tabular}

$(3.14 \mathrm{MJ} / \mathrm{kg})$ was calculated as follows: $\mathrm{ECM}=$ milk yield $\times(383 \times$ fat $\%+242 \times$ protein $\%+783.2) / 3,140$ (Sjaunja et al., 1991).

On d 20 of each experimental period, rumen fluid samples were taken from animals by stomach tube with a vacuum pump $4 \mathrm{~h}$ after the morning feeding and were checked to have no saliva. The $\mathrm{pH}$ was measured immediately with a portable $\mathrm{pH}$ meter (Metrohm 744, Herisau, Switzerland). The rumen fluid samples were strained through 4 layers of cheesecloth and prepared for subsequent ammonia- $\mathrm{N}$ ( $5 \mathrm{~mL}$ of rumen fluid was acidified with $5 \mathrm{~mL}$ of $0.2 \mathrm{~N} \mathrm{HCl})$ and VFA $(5 \mathrm{~mL}$ of rumen fluid was mixed with $1 \mathrm{~mL}$ of $250 \mathrm{~g} / \mathrm{L}$ of metaphosphoric acid) analyses. Ruminal subsamples were frozen at $-20^{\circ} \mathrm{C}$ until laboratory analyses.

On the last day of each experimental period, blood samples were collected from a jugular vein $(10 \mathrm{~mL}$ into sterile tubes containing EDTA solution) $4 \mathrm{~h}$ after the morning feeding. The samples were immediately placed on ice for processing in the laboratory. The blood samples were then centrifuged at 3,000 $\times g$ for $15 \mathrm{~min}$ at $4^{\circ} \mathrm{C}$. Plasma was harvested and stored at $-20^{\circ} \mathrm{C}$ until analysis.

\section{Laboratory Analysis}

Composited dietary samples were ground to pass through a 2-mm screen in a Wiley mill (standard model 4; Arthur H. Thomas Co., Philadelphia, PA) before chemical analyses. Samples were analyzed for DM $\left(135^{\circ} \mathrm{C}\right.$; AOAC International, 2000; method 930.15), ash $\left(535^{\circ} \mathrm{C}\right.$; AOAC International, 2000; method 942.05$), \mathrm{CP}$ (AOAC International, 2000; method 990.03), and ether extract (AOAC International, 2000; method 920.39). Concentrations of ADF and NDF inclusive of residual ash, were determined without sodium sulfite and with the inclusion of heat-stable $\alpha$-amylase $(100 \mathrm{~mL} / 0.5 \mathrm{~g}$ of sample; Van Soest et al., 1991). The nonfiber carbo- 
hydrate content (\% of DM) of the diets was calculated as $100-(\mathrm{NDF}+\mathrm{CP}+$ ether extract + ash $)$. Total ethanol-soluble carbohydrates and starch were determined according to the procedure of Hall et al. (1999).

Analysis of the fatty acid content of the feeds was performed according to ISIRI (1997). Individual milk samples were analyzed for fat, CP, and lactose concentrations by Milko-Scan 605 analyzer (Foss Electric, Hillerød, Denmark). For analysis of milk fatty acid, milk fat was extracted using a centrifugation technique described by Luna et al. (2005). Subsequently, about 100 mg of the milk fat was mixed with $2 \mathrm{~mL}$ of $1 \mathrm{M} \mathrm{KOH}$, and then $5 \mathrm{~mL}$ of $14 \%$ boron trifluoride in ethanol was added. The sample was methylated at $100^{\circ} \mathrm{C}$ for $60 \mathrm{~min}$ and then extracted with $5 \mathrm{~mL}$ of hexane (ISIRI, 1997). The FAME in the hexane layer were analyzed with a gas chromatograph (3400 Varian Star, Varian Inc., Palo Alto, CA) equipped with CP-SIL-88 capillary column (Chrompack, $60 \mathrm{~m} \times 0.25 \mathrm{~mm}$, Varian) and helium was the carrier gas. Column temperature was initially $50^{\circ} \mathrm{C}$ for $1 \mathrm{~min}$, and increased by $10^{\circ} \mathrm{C} / \mathrm{min}$ to $190^{\circ} \mathrm{C}$ for another $130 \mathrm{~min}$. The temperature of the injector was $280^{\circ} \mathrm{C}$, and that of the detector was $300^{\circ} \mathrm{C}$. Peaks of FAME were identified by comparing their retention times with those of the standard mixture 37 Component FAME Mix (Supelco, Bellefonte, PA). Quantification of fatty acid was based on tridecanoic acid (13:0, Sigma, St. Louis, MO) as an internal standard.

Ruminal ammonia-N was analyzed by the distillation method (Kjeltec Auto 1030 Analyzer Tecator, Hoganas, Sweden), and the concentrations of VFA were determined by gas chromatography (Chrompack, model CP-9002, Chrompack, EA Middelburg, the Netherlands) equipped with a $50-\mathrm{m}$ (0.32 mm i.d.) silica-fused column (CP-Wax Chrompack Capillary Column, Varian). Helium and crotonic acid (trans-2-butenoic acid) were used as carrier gas and the internal standard, respectively. Oven initial and final temperatures were 55 and $195^{\circ} \mathrm{C}$, respectively, and detector and injector temperatures were set at $250^{\circ} \mathrm{C}$.

Blood metabolite concentrations were determined by an autoanalyzer (Alcyon 300i, Abbott, Abbott Park, IL) using commercially available kits [Pars Azmoon Company, catalog numbers: glucose (1-500-017), triglyceride (TG; 1-500-032), cholesterol (1-500-010), and urea nitrogen (BUN; 1-400-029), Tehran, Iran] according to the manufacturer's instructions.

\section{Statistical Analysis}

The compiled data were analyzed using the MIXED procedure of SAS (SAS Institute Inc., 2003). Period, $\mathrm{SC}, \mathrm{SF}$, and their 2-way interactions were considered as fixed effects in the model. The random statement included square and cow within square. The model used for intake, production, ruminal characteristics, milk fatty acid profile, and blood metabolites data is shown below:

$$
\begin{gathered}
\mathrm{Y}_{\mathrm{ijklm}}=\mu+\mathrm{S}_{\mathrm{i}}+\mathrm{C}_{\mathrm{j}(\mathrm{i})}+\mathrm{P}_{\mathrm{k}}+\mathrm{M}_{\mathrm{l}} \\
+\mathrm{F}_{\mathrm{m}}+(\mathrm{M} \times \mathrm{F})_{l \mathrm{~lm}}+\mathrm{e}_{\mathrm{ijk} \mathrm{klm}},
\end{gathered}
$$

where $\mu$ is the overall mean; $\mathrm{S}_{\mathrm{i}}$ is the random effect of square (1 to 2); $\mathrm{C}_{\mathrm{j}(\mathrm{i})}$ is the random effect of cow within square (1 to 4$) ; \mathrm{P}_{\mathrm{k}}$ is the fixed effect of period ( 1 to 4); $\mathrm{M}_{\mathrm{l}}$ is the fixed effect of SC (1 to 2 ); $\mathrm{F}_{\mathrm{m}}$ is the fixed effect of SF (1 to 2); $(\mathrm{M} \times \mathrm{F})_{\mathrm{lm}}$ is the fixed effect of the interaction of $\mathrm{M}_{1}$ and $\mathrm{F}_{\mathrm{m}}$; and $\mathrm{e}_{\mathrm{ijklm}}$ is the random residual error, assumed to be normally distributed. The interaction between each main effect and square was tested, but excluded from the model because it was not significant. Least squares means procedure was used to detect the difference between the means of dietary treatments. Significance was declared at $P \leq 0.05$, and trends were considered when $0.05<P \leq 0.10$.

\section{RESULTS AND DISCUSSION}

\section{Feed Intake}

As expected, all diets contained similar contents of $\mathrm{DM}, \mathrm{CP}$, and $\mathrm{OM}$ (Table 1). As a direct consequence of the incorporation of $\mathrm{SF}$, the $\mathrm{NSC}+\mathrm{SF}$ and $\mathrm{SC}+\mathrm{SF}$ diets contained higher ether extract (6.4 and 6.2 vs. $3.5 \%$ ) and $\mathrm{NE}_{\mathrm{L}}$ (1.66 and 1.68 vs. 1.64 and $1.65 \mathrm{Mcal} /$ $\mathrm{kg}$ of DM) contents than the NSC-SF and SC-SF diets (Table 1). In the current study, SF-supplemented diets contained less canola meal and more sugar beet pulp level compared with unsupplemented diets to formulate iso-nitrogenous and iso-energetic diets; thus, we cannot fully conclude whether these effects were due to SF and SC. The major fatty acid in diets was cis-9,cis-12 18:2; however, the addition of SF increased the total dietary lipid content, 18:0, cis-9 18:1, and cis-9,cis-12 18:2 in the NSC+SF and SC + SF compared with NSC-SF and SC-SF diets (Table 2).

No sugar $\times$ oil interaction was found on DMI (Table $3)$. The diets with no added SC in the current study were close to the optimal level of total sugar content (5\% of DM basis) as recommended by Broderick and Radloff (2004) based on milk response, and the diets containing SC were above this range. However, no reports in the current literature show negative effects on DMI of feeding sugars. Firkins (2010) claimed sugars are more likely to stimulate DMI and milk fat yield 
Table 2. Fatty acid profile (\% of total FAME) of diets

\begin{tabular}{lccrr}
\hline & \multicolumn{4}{c}{ Dietary treatment } \\
\cline { 2 - 5 } Item & NSC-SF & NSC+SF & SC-SF & SC+SF \\
\hline 12:0 & 1.4 & 0.6 & 1.1 & 0.4 \\
$14: 0$ & 1.4 & 1.4 & 1.0 & 1.7 \\
$16: 0$ & 27.1 & 16.6 & 28.1 & 19.0 \\
cis-9 16:1 & 1.2 & 0.7 & 1.5 & 0.4 \\
18:0 & 3.8 & 4.4 & 4.2 & 5.5 \\
cis-9 18:1 & 26.9 & 29.1 & 27.4 & 28.9 \\
cis-9, cis-12 18:2 & 34.7 & 41.8 & 32.1 & 39.7 \\
cis-9, cis-12,cis-15 18:3 & 2.6 & 1.8 & 2.7 & 2.0 \\
cis-9 20:1 & 0.7 & 1.2 & 1.0 & 0.9 \\
22:0 & - & 0.5 & 0.9 & 0.4 \\
cis-9 22:1 & - & 1.0 & - & 0.4 \\
\hline
\end{tabular}

${ }^{1}$ Dietary treatments: NSC-SF $=$ no additional sucrose (SC) without sunflower seed (SF) supplementation; $\mathrm{NSC}+\mathrm{SF}=$ no additional SC with SF supplementation; SC-SF = SC without SF supplementation; and SC+SF $=\mathrm{SC}$ with SF supplementation.

when NFC and especially rumen-degraded starch are kept at moderate concentrations (NFC, $37 \%$ and starch, $25 \%$ of DM). Martel et al. (2011) did not detect a feed intake response in diets with very high NFC level (NFC $=46 \%$ of $\mathrm{DM}$ ), which is consistent with our findings ( $\mathrm{NFC}=41.54 \%$ in SC-SF diet). Therefore, higher DMI in some studies (Broderick et al., 2008; Penner and Oba, 2009) in response to dietary greater sugar may be regarded as responses to moderate concentrations of dietary NFC and starch.

In the current study, SF did not affect DMI, which is consistent with findings of Petit et al. (2004). The level of fat in the NSC+SF and $\mathrm{SC}+\mathrm{SF}$ diets were within the NRC (2001) guidelines for dairy diets, which recommends an upper limit of 3 to $4 \%$ DM supplemented fat and 6 to $7 \% \mathrm{DM}$ total fat in the diet.

\section{Ruminal Fermentation}

The data for rumen fermentation parameters are presented in Table 3. No interactions were detected between SC concentration and SF supplementation with respect to rumen fermentation characteristics. Regardless of the inclusion of SF, cows fed SC diets had greater ruminal $\mathrm{pH}$ than those fed no additional $\mathrm{SC}$ diets $(P<0.01)$. The effect of sugars on rumen $\mathrm{pH}$ in the literature is somewhat inconsistent. Rapid fermentation of sugars relative to the other carbohydrate fractions is expected to increase lactic acid production (Oelker et al., 2009) and decrease ruminal pH (Oba et al., 2015). Considering these observations, elevated rumen $\mathrm{pH}$ in the current study is somewhat surprising; however, this is consistent with findings by other authors. A few

Table 3. Effects of sucrose (SC) and sunflower seed (SF) inclusion on feed intake and ruminal fermentation characteristics

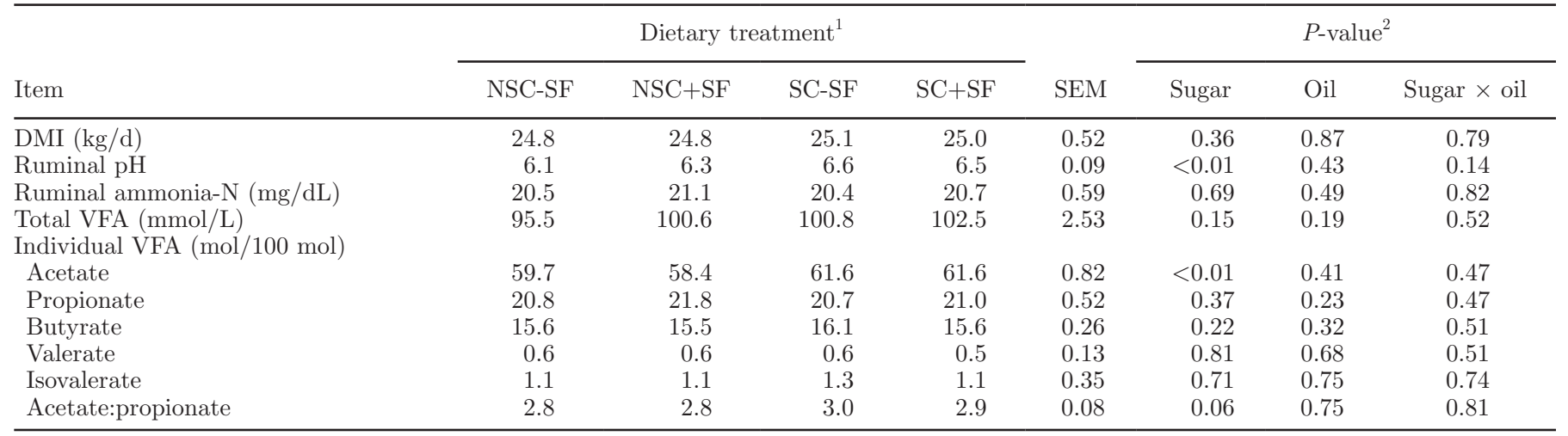

${ }^{1}$ Dietary treatments: NSC-SF $=$ no additional SC without SF supplementation; NSC+SF = no additional SC with SF supplementation; SC-SF $=\mathrm{SC}$ without $\mathrm{SF}$ supplementation; and $\mathrm{SC}+\mathrm{SF}=\mathrm{SC}$ with $\mathrm{SF}$ supplementation.

${ }^{2}$ Statistical comparisons: sugar $=$ level of sucrose; oil $=$ the presence or absence of sunflower seed supplement. 
studies have reported that replacing a dietary starch source with sugars tended to increase (Penner et al., 2009; Penner and Oba, 2009) or decrease (Razzaghi et al., 2015) or have no effect on rumen $\mathrm{pH}$ (Broderick et al., 2008; Oelker et al., 2009). According to a review by Oba (2011), the majority of in vivo studies reported that rumen $\mathrm{pH}$ is not affected by feeding sugars. The discrepancy may be attributed to the unique experimental settings of some studies, as well as differences in fermentability of basal diets, carbohydrate digestion, and sugar or animal type, or some combination of these effects (Weisbjerg et al., 1998; Oelker et al., 2009). Sampling differences may also be responsible for discrepancies between studies. In the current experiment, rumen fluid was only collected at one time point, and it is possible that these results are not representative of the whole day.

The ruminal ammonia- $\mathrm{N}$ concentration in the current study was not affected by diets, which is in agreement with the results reported by Penner and Oba (2009) as well as Razzaghi et al. (2015). The total VFA concentration in the current study was not affected by sugar content. Similarly, Penner and Oba (2009) had not observed any differences in total rumen VFA concentrations between cows fed high-sugar diets compared with low-sugar diets ( 8.7 vs. $4.5 \%$ of DM). Nonetheless, fermentation may have been stabilized by the storage of sugar as glycogen by protozoa and some bacteria, as reported by Hall and Weimer (2007). Moreover, fermentation rates are different depending on the type of sugar (Weisbjerg et al., 1998), and their effects on rumen $\mathrm{pH}$ and VFA profile are also variable (Oba et al., 2015).

Regardless of SF supplementation, cows fed SC diets had greater molar proportion of ruminal acetate (Table 3; $P<0.01$ ), which resulted in a tendency for a greater acetate-to-propionate ratio for those fed diets with added SC $(P=0.06)$. This finding is consistent with the results reported by Martel et al. (2011). In the current study, the molar proportions of ruminal propionate, butyrate, valerate, and isovalerate were similar across treatments. The effects of feeding sugar on ruminal propionate and butyrate concentrations have been somewhat variable. Studies where sugar partly replaced dietary starch showed that the molar proportion of propionate was decreased (DeFrain et al., 2004), increased (Razzaghi et al., 2015), or not affected (Vallimont et al., 2004). Shingfield et al. (2008) noted that supplementation of diets with sunflower oil at the highest level of inclusion ( $7.5 \%$ of DM) shifted rumen fermentation toward propionate at the expense of acetate. Differences between our study and the study of Shingfield et al. (2008) were likely due to the lower ether extract level and the satisfactory NDF content of the diets in our study. The molar proportion of butyrate in the rumen fluid did not differ between diets (Broderick et al., 2008), or tended to decrease (McCormick et al., 2001) by partial replacement of corn grain with SC. Leek (1993) reported that the absorption rate of butyrate is faster than that of acetate or propionate in the rumen and it may be difficult to detect increases in ruminal butyrate concentration even if sugar fermentation increases butyrate production. The results obtained for the molar proportion of valerate and isovalerate are in agreement with those reported by Broderick et al. (2008) who showed that feeding SC in place of starch did not increase valerate concentration.

\section{Milk Yield and Composition}

The data for milk yield and composition are presented in Table 4. A tendency was found for an interaction between sugar and SF on ECM, with a more pronounced change for cows fed diets with added SC (SC-SF and $\mathrm{SC}+\mathrm{SF} ; P \leq 0.10)$. In the current study, milk fat yield was higher in cows fed SC diets compared with those fed no additional SC diets $(P<0.01$, SC-SF diet $)$. Milk yield, milk protein, lactose, and solid-nonfat percentage and yields were similar across diets regardless of SC or SF supplementation. The effect of sugars on milk yield have been variable, with some studies reporting increases in milk yield (Broderick and Radloff, 2004) and others reporting no significant effect of sugar supplementation on milk yield (Broderick et al., 2008). It is not surprising that milk yield was not different in our study, considering that DMI was not increased for cows fed diets containing SC. However, feeding SC increased milk fat percentage and yield in dairy cows, which is in agreement with results obtained in previous studies (Broderick et al., 2008; Martel et al., 2011). This may be attributed to a lower proportion of total trans-fatty acid in milk fat (Table 5; Siverson et al., 2014) or alterations in rumen fermentation pattern inconsistent with the higher ruminal $\mathrm{pH}$ and acetate proportion for cows fed SC diet (Martel et al., 2011). Although inclusion of SC in the diet increased milk fat content with the highest mean observed for SC-SF treatment, a trend for a decrease in milk fat concentration was observed when $\mathrm{SF}$ was added to diets $(P=0.07)$; however, their interaction was not significant. This response may partly be attributed to increased formation of specific $\mathrm{BH}$ intermediates in the rumen (trans-fatty acid formation) following PUFA supplementation that served to limit or minimize the increase in milk fat content typically reported in cows. The present results were in line with previous studies where dietary sugar had no effects on milk protein concentration and yield in dairy cows (Broderick et al., 2008; Penner and Oba, 2009). 
Regarding milk yield, our findings are in agreement with those of Petit et al. (2004), who found no effect of SF on milk yield. Rabiee et al. (2012) claimed that the milk yield responses to fats are very heterogeneous. Factors thought to influence milk production responses include the stage of lactation when supplements are fed, effects of fats on DMI, and supplemental fat sources (Block and Evans, 2010).

\section{Milk Fatty Acid Profiles}

The data for the milk fatty acid profile are presented in Table 5. Interactions were found between sugar content and SF with respect to some fatty acids (10:0, 12:0, 16:0, cis-9 16:1, and 18:0) measured. In the current study, the main milk fatty acids was not affected by SC inclusion, with the exception of total trans-fatty acid $(P<0.05)$. The present finding is consistent with the reduction in trans-10 18:1 proportion in milk fat due to the inclusion of molasses to diets reported by Martel et al. (2011) and Siverson et al. (2014), who evaluated the effect of supplementing a high-concentrate and typical lactation diet, respectively.

The concentration of 16:0 was affected by the interaction between dietary sugar and $\mathrm{SF}$, with a more pronounced decrease for cows fed SC diets (SC-SF vs. $\mathrm{SC}+\mathrm{SF}$ ) than those fed diets without added SC (NSC$\mathrm{SF}$ vs. NSC+SF). Furthermore, the concentration of 16:0 decreased in milk fat of cows fed the oilseed-supplemented diets (NSC+SF and $\mathrm{SC}+\mathrm{SF}$ diets) compared with other treatments. This result is likely due to the inhibitory effects of LCFA on de novo synthesis in the mammary gland (Glasser et al., 2008). Similar effects of SF supplementation on the concentration of 16:0 have been reported by Roy et al. (2006).
In the current study, SF supplementation increased the concentration of milk 18:0, cis-9 18:1, total trans-18:1, cis-9,cis-12 18:2, and total CLA in milk fat $(P<0.01)$. The increase in the concentration of 18:0 with SF is likely due to an increase in mammary uptake of C18 fatty acid (Roy et al., 2006). In the study of Mohammed et al. (2011), milk fatty acid composition of cows fed diets supplemented with various sources of LCFA revealed that trans-11 18:1 and cis-9,trans-11 CLA concentrations were greater for the SF diet compared with palm oil, flaxseed, or canola seed diets. Furthermore, the concentration of cis-9,cis-12,cis-15 18:3 tended $(P=0.09)$ to decrease by SF supplementation.

Diets containing SF decreased the concentrations of short-chain fatty acids (4:0 to 10:0) and medium-chain fatty acids $(12: 0$ to $16: 0)$ in milk fat $(P<0.01)$, probably because of the potential inhibitory effect of the dietary PUFA on milk fat synthesis (Chilliard et al., 2007 ) or the inhibiting role of several trans-18 isomers produced in the rumen on de novo fatty acid synthesis in the mammary gland (Shingfield et al., 2010). In line with results of the present study, Roy et al. (2006) demonstrated a remarkable reduction in 10:0 to $16: 0$ secretions to milk in cows on diets containing sunflower oil. Moreover, feeding SF increased the total concentration of long-chain fatty acids, PUFA, and total trans-fatty acid concentrations, consistent with previous studies (Table 5; Roy et al., 2006; Bernard et al., 2009; Razzaghi et al., 2015).

Trans-16:1 percentage was not significantly affected, possibly because of its ruminal origin; however, an interaction was found between SC and SF on cis-9 16:1 $(P=0.05)$. Inclusion of $\mathrm{SC}$ did not change the $\Delta^{9}$ desaturation index (quantified as 14:1/14:0; Table 6). However, Martel et al. (2011) revealed that molasses

Table 4. Effects of sucrose (SC) and sunflower seed (SF) inclusion on milk yield and composition

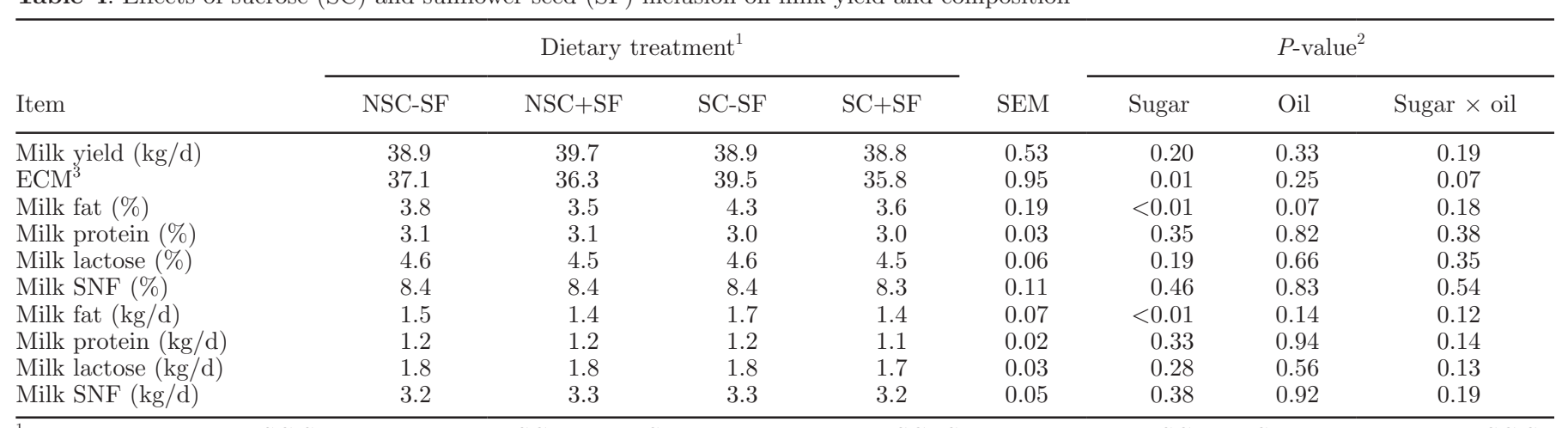

\footnotetext{
${ }^{1}$ Dietary treatments: NSC-SF $=$ no additional SC without SF supplementation; NSC+SF = no additional SC with SF supplementation; SC-SF $=\mathrm{SC}$ without $\mathrm{SF}$ supplementation; and $\mathrm{SC}+\mathrm{SF}=\mathrm{SC}$ with $\mathrm{SF}$ supplementation.

${ }^{2}$ Statistical comparisons: sugar $=$ level of sucrose; oil $=$ the presence or absence of sunflower seed supplement.

${ }^{3}$ Energy-corrected milk calculated as described by Sjaunja et al. (1991).
} 
Table 5. Effects of sucrose (SC) and sunflower seed (SF) inclusion on milk fatty acid profile (\% of total FAME)

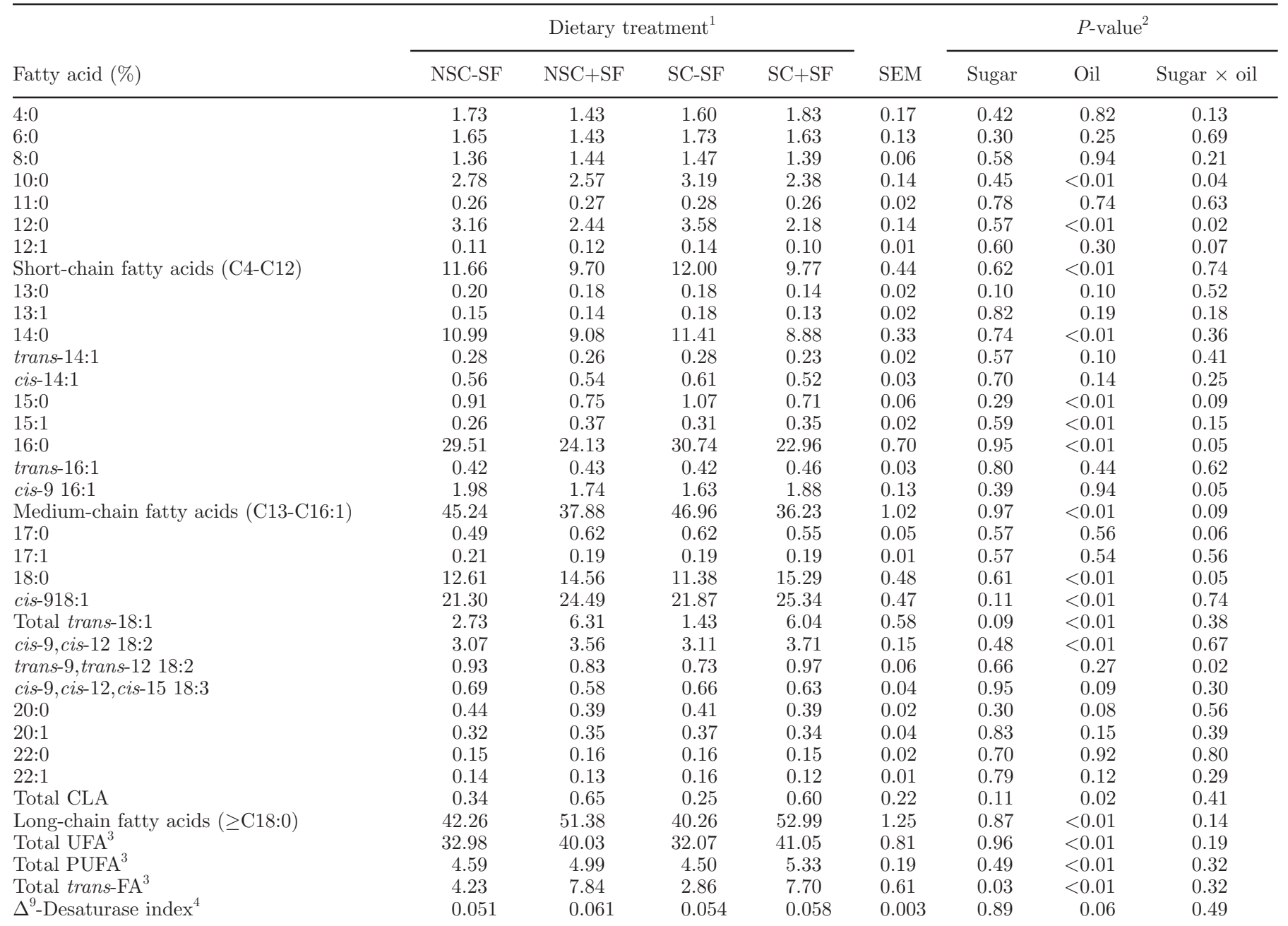

${ }^{1}$ Dietary treatments: NSC-SF $=$ no additional SC without SF supplementation; NSC+SF = no additional SC with SF supplementation; SC-SF $=\mathrm{SC}$ without $\mathrm{SF}$ supplementation; and $\mathrm{SC}+\mathrm{SF}=\mathrm{SC}$ with $\mathrm{SF}$ supplementation.

${ }^{2}$ Statistical comparisons: sugar $=$ level of sucrose; oil $=$ the presence or absence of sunflower seed supplement.

${ }^{3} \mathrm{UFA}=\mathrm{C} 12: 1+\mathrm{C} 13: 1+\mathrm{C} 14: 1+\mathrm{C} 15: 1+\mathrm{C} 16: 1+\mathrm{C} 17: 1+\mathrm{C} 18: 1+\mathrm{C} 18: 2+\mathrm{C} 18: 3+\mathrm{C} 20: 1+\mathrm{C} 22: 1$ (cis/trans isomers) PUFA $=18: 2+$ 18:3 (cis/trans isomers); total trans-fatty acid = trans-14:1 + trans-16:1 + trans-18:1 + trans/trans-18:2.

${ }^{4}$ Calculated according to Bouattour et al. (2008) as (product of $\Delta^{9}$-desaturase)/(product of $\Delta^{9}$-desaturase + substrate of $\Delta^{9}$-desaturase); that is for C14: C14:1/(C14:1 + C14:0).

Table 6. Effects of sucrose (SC) and sunflower seed (SF) inclusion on blood metabolites

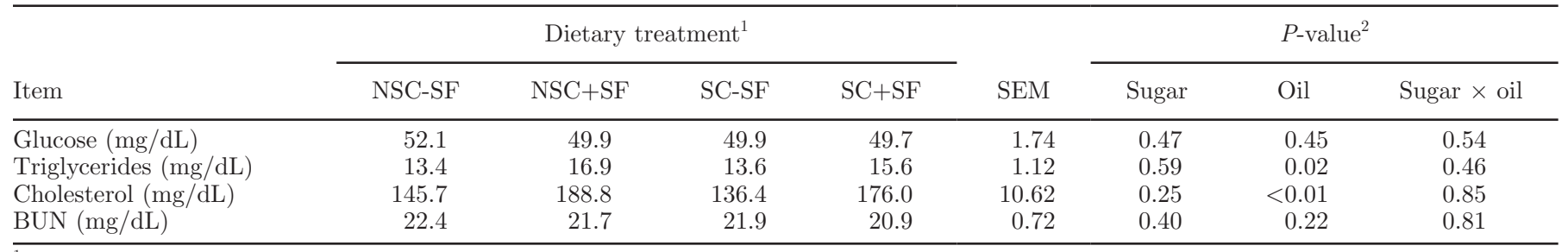

${ }^{1}$ Dietary treatments: NSC-SF $=$ no additional SC without SF supplementation; NSC+SF = no additional SC with SF supplementation; SC-SF $=\mathrm{SC}$ without $\mathrm{SF}$ supplementation; and $\mathrm{SC}+\mathrm{SF}=\mathrm{SC}$ with $\mathrm{SF}$ supplementation.

${ }^{2}$ Statistical comparisons: sugar $=$ level of sucrose; oil $=$ the presence or absence of sunflower seed supplement. 
decreased the $\Delta^{9}$-desaturation index because of lower proportion of UFA in milk with molasses inclusion.

\section{Blood Metabolites}

The data for blood metabolites are presented in Table 6 . No interactions were detected between dietary sugar content and SF supplementation with respect to blood metabolites. The blood glucose concentration in the current study was not affected by treatments, which is in agreement with the results of Razzaghi et al. (2015). Regardless of the SC addition, cows fed diets supplemented with SF had greater concentrations of blood triglycerides and cholesterol. According to Douglas et al. (2004), such change may be due to an increasing amount of LCFA reaching the small intestine and subsequently increased cholesterol in plasma. Data obtained from the current study are in line with results of Bernard et al. (2009), where goats supplemented with sunflower oil (6.1\% of diet DM) had greater plasma concentrations of triglyceride and cholesterol compared with unsupplemented goats. Results regarding BUN concentration herein are in agreement with those reported by Broderick et al. (2008), who did not find differences in BUN when SC replaced dietary starch in the diets of dairy cows.

\section{CONCLUSIONS}

Replacement of corn grain with SC increased milk fat yield, but had no effect on DMI and milk yield, although ECM was greater in cows who received supplemental sugar. Most of the effects observed on milk fatty acid profile in this study were due to SF supplementation.

\section{ACKNOWLEDGMENTS}

This study was supported by Ferdowsi University of Mashhad (Mashhad, Iran). The authors express their appreciation to A. Mahdavi and B. Abasnezhad (farm staff at Research Center of Dairy cow, Faculty of Agriculture, Ferdowsi University of Mashhad) for the cooperation. We gratefully acknowledge B. J. Bradford (Department of Animal Sciences and industry, Kansas State University, Manhattan) for scientific assistance.

\section{REFERENCES}

AOAC International. 2000. Official Methods of Analysis. 18th ed. AOAC International, Gaithersburg, MD.

Bernard, L., M. Bonnet, C. Leroux, K. J. Shingfield, and Y. Chilliard. 2009. Effect of sunflower-seed oil and linseed oil on tissue lipid metabolism, gene expression, and milk fatty acid secretion in alpine goats fed maize silage-based diets. J. Dairy Sci. 92:6083-6094.
Block, E., and E. Evans. 2010. A model to compare effects of supplemental fat sources on performance and dry matter intake in dairy cows: Effects of fat inclusion level. J. Dairy Sci. 93(E-Suppl.1):440. (Abstr.)

Bouattour, M. A., R. Casals, E. Albanell, X. Such, and G. Caja. 2008. Feeding soybean oil to dairy goats increases conjugated linoleic acid in milk. J. Dairy Sci. 91:2399-2407.

Broderick, G. A., N. D. Luchini, S. M. Reynal, G. A. Varga, and V. A. Ishler. 2008. Effect on production of replacing dietary starch with sucrose in lactating dairy cows. J. Dairy Sci. 91:4801-4810.

Broderick, G. A., and W. J. Radloff. 2004. Effect of molasses supplementation on the production of lactating dairy cows fed diets based on alfalfa and corn silage. J. Dairy Sci. 87:2997-3009.

Chilliard, Y., F. Glasser, A. Ferlay, L. Bernard, J. Rouel, and M. Doreau. 2007. Diet, rumen biohydrogenation and nutritional quality of cow and goat milk fat. Eur. J. Lipid Sci. Technol. 109:828855.

DeFrain, J. M., A. R. Hippen, K. F. Kalscheur, and D. J. Schingoethe. 2004. Feeding lactose increases ruminal butyrate and plasma betahydroxybutyrate in lactating dairy cows. J. Dairy Sci. 87:24862494.

Douglas, G. N., T. R. Overton, H. G. Bateman, and J. K. Drackley. 2004. Peripartal metabolism and production of Holstein cows fed diets supplemented with fat during the dry period. J. Dairy Sci. $87: 4210-4220$.

Firkins, J. L. 2010. Addition of sugars to dairy rations. Pages 91-105 in Proc. Tri-State Dairy Nutrition, Wayne, IN. Press Works Inc., Plain City, $\mathrm{OH}$.

Glasser, F., A. Ferlay, and Y. Chilliard. 2008. Oilseed lipid supplements and fatty acid composition of cow milk: A meta-analysis. J. Dairy Sci. 91:4687-4703.

Hall, M. B., W. H. Hoover, J. P. Jennings, and T. K. Miller-Webster. 1999. A method for partitioning neutral detergent-soluble carbohydrates. J. Sci. Food Agric. 79:2079-2086.

Hall, M. B., and P. J. Weimer. 2007. Sucrose concentration alters fermentation kinetics, products, and carbon fates during in vitro fermentation with mixed ruminal microbes. J. Anim. Sci. 85:14671478.

Institute of Standard and Industrial Research of Iran (ISIRI). 1997. Animal and vegetable fats and oil (methods 4090 and 4091). ISIRI, Karaj, Iran.

Iranian Council of Animal Care. 1995. Guide to the Care and Use of Experimental Animals. Vol. 1. Isfahan University of Technology, Isfahan, Iran.

Leek, B. F. 1993. Digestion in the ruminant stomach. Pages 387-416 in Dukes' Physiology of Domestic Animals. 11th ed. M. J. Swenson and W. O. Reece, ed. Cornell University Press, Ithaca, NY.

Luna, P., M. Juárez, and M. A. de la Fuente. 2005. Validation of a rapid milk fat separation method to determine the fatty acid profile by gas chromatography. J. Dairy Sci. 88:3377-3381.

Martel, C. A., E. C. Titgemeyer, L. K. Mamedova, and B. J. Bradford. 2011. Dietary molasses increases ruminal $\mathrm{pH}$ and enhances ruminal biohydrogenation during milk fat depression. J. Dairy Sci. 94:3995-4004.

McCormick, M. E., D. D. Redfearn, J. D. Ward, and D. C. Blouin. 2001. Effect of protein source and soluble carbohydrate addition on rumen fermentation and lactation performance of Holstein cows. J. Dairy Sci. 84:1686-1697.

Mohammed, R., S. M. McGinn, and K. A. Beauchemin. 2011. Prediction of enteric methane output from milk fatty acid concentrations and rumen fermentation parameters in dairy cows fed sunflower, flax, or canola seeds. J. Dairy Sci. 94:6057-6068.

Mullins, C. R., and B. J. Bradford. 2010. Effects of molasses-coated cottonseed product on diet digestibility, performance, and milk fatty acid profile of lactating dairy cattle. J. Dairy Sci. 93:31283135 .

National Research Council. 2001. Nutrient Requirements of Dairy Cattle. 7th rev. ed., National Academic Press, Washington, DC.

Oba, M. 2011. Review: Effects of feeding sugars on productivity of lactating dairy cows. Can. J. Anim. Sci. 91:37-46. 
Oba, M., J. L. Mewis, and Z. Zhining. 2015. Effects of ruminal doses of sucrose, lactose, and corn starch on ruminal fermentation and expression of genes in ruminal epithelial cells. J. Dairy Sci. 98:586-594.

Oelker, E. R., C. Reveneau, and J. L. Firkins. 2009. Interaction of molasses and monensin in alfalfa hay- or corn silage-based diets on rumen fermentation, total tract digestibility, and milk production by Holstein cows. J. Dairy Sci. 92:270-285.

Penner, G. B., L. L. M. Guan, and M. Oba. 2009. Effects of feeding Fermenton on ruminal fermentation in lactating Holstein cows fed two dietary sugar concentrations. J. Dairy Sci. 92:1725-1733.

Penner, G. B., and M. Oba. 2009. Increasing dietary sugar concentration may improve dry matter intake, ruminal fermentation and productivity of dairy cows in the postpartum phase of the transition period. J. Dairy Sci. 92:3341-3353.

Petit, H. V., C. Germiquet, and D. Lebel. 2004. Effect of feeding whole, unprocessed sunflower seeds and flaxseed on milk production, milk composition, and prostaglandin secretion in dairy cows. J. Dairy Sci. 87:3889-3898.

Rabiee, A. R., K. Breinhild, W. Scott, H. M. Golder, E. Block, and I. J. Lean. 2012. Effect of fat additions to diets of dairy cattle on milk production and components: A meta-analysis and metaregression. J. Dairy Sci. 95:3225-3247.

Razzaghi, A., R. Valizadeh, A. A. Naserian, M. Danesh-Mesgaran, and L. Rashidi. 2015. Effects of sucrose and sunflower oil addition to diet of Saanen dairy goats on performance and milk fatty acid profile. Livest. Sci. 172:14-23.

Roy, A., A. Ferlay, K. J. Shingfield, and Y. Chilliard. 2006. Examination of the persistency of milk fatty acid composition responses to plant oils in cows fed different basal diets, with particular emphasis on trans-C18:1 fatty acids and isomers of conjugated linoleic acid. J. Anim. Sci. 82:479-492.

SAS Institute Inc. 2003. SAS/STAT User's Guide: Version 9.1. SAS Institute Inc., Cary, NC.
Shingfield, K. J., S. Ahvenjarvi, V. Toivonen, A. Vanhatalo, P. Huhtanen, and J. M. Griinari. 2008. Effect of incremental levels of sunflower-seed oil in the diet on ruminal lipid metabolism in lactating cows. Br. J. Nutr. 99:971-983.

Shingfield, K. J., L. Bernard, C. Leroux, and Y. Chilliard. 2010. Role of trans-fatty acids in the nutritional regulation of mammary lipogenesis in ruminants. Animal 4:1140-1166.

Siverson, A., C. F. Vargas-Rodriguez, and B. J. Bradford. 2014. Short communication: Effects of molasses products on productivity and milk fatty acid profile of cows fed diets high in dried distillers grains with solubles. J. Dairy Sci. 97:3860-3865.

Sjaunja, L. O., L. Baevre, L. Junkkarinen, J. Pedersen, and J. Setala. 1991. A Nordic proposal for an energy corrected milk (ECM) formula. EAAP Publication 50. Pages 156-157 in Performance Recording of Animals-State of the Art 1990. Centre for Agricultural Publishing and Documentation (PUDOC), Wageningen, the Netherlands.

Vallimont, J. E., F. Bargo, T. W. Cassidy, N. D. Luchini, G. A. Broderick, and G. A. Varga. 2004. Effects of replacing dietary starch with sucrose on ruminal fermentation and nitrogen metabolism in continuous culture. J. Dairy Sci. 87:4221-4229.

Van Soest, P. J., J. B. Robertson, and B. A. Lewis. 1991. Methods of dietary fiber, neutral detergent fiber, and non-starch polysaccharides in relation to animal nutrition. J. Dairy Sci. 74:3583-3597.

Weisbjerg, M. R., T. Hvelplund, and B. M. Bibby. 1998. Hydrolysis and fermentation rate of glucose, sucrose and lactose in the rumen. Acta Agric. Scand. Anim. Sci. 48:12-18.

Zened, A., F. Enjalbert, M. C. Nicot, and A. Troegeler-Meynadier. 2013. Starch plus sunflower oil addition to the diet of dry dairy cows results in a trans-11 to trans-10 shift of biohydrogenation. J. Dairy Sci. 96:451-459. 